\title{
A family with primary protrusio acetabuli
}

\author{
K. D'ARCY, B. M. ANSELL, AND E. G. L. BYWATERS \\ From the Juvenile Rheumatism Unit, Canadian Red Cross Memorial Hospital, Taplow, Maidenhead, Berks
}

SUMMARY The family of a child who developed symptoms and flexion contractures with protrusio acetabuli rapidly between the age of 8 and 11 was examined. The mother and one sib showed limitation of hip movements, while radiological criteria for protrusio were found in the mother and 4 of the proband's 8 sibs; only one had complained of pain. At the age of 16 the proband underwent bilateral total replacement arthroplasty; histologically the changes were those of fibrocartilaginous replacement and osteophyte formation.

Protrusio acetabuli, described by Otto in 1816, is a disorder in which the acetabulum and femoral head are displaced medially into the pelvic cavity. It may be secondary to other disorders affecting the hip joint or bone generally, e.g. osteoarthrosis, rheumatoid arthritis, Paget's disease etc. (Golding, 1934; Overgaard, 1935), or it may arise de novo, designated 'primary'. We describe a girl who developed acute symptoms related to the hips, not secondary to other disease. Other members of the family were also affected (Fig. 1).

\section{Case report}

D.F., an 11-year-old girl, presented with acute pain in the right hip, a limp, and increasing stiffness. Her mother had noticed that she had walked awkwardly for the preceding 2 to 3 years, from the age of 8 years.

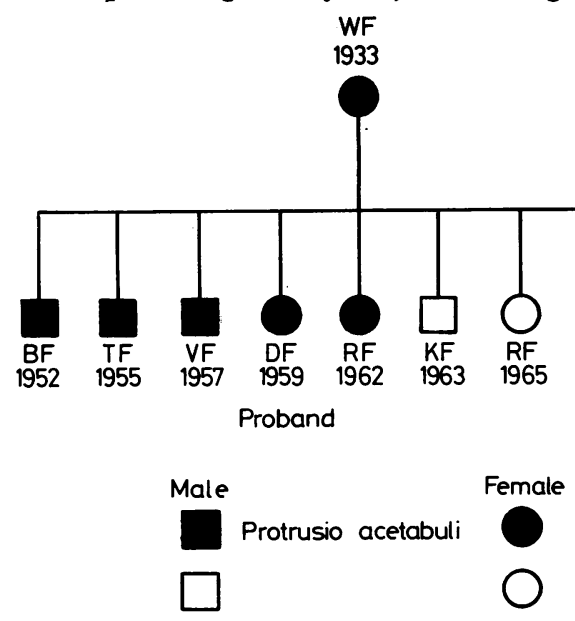

Fig. 1 Family pedigree.

Accepted for publication July 12, 1977 Correspondence to Dr B. M. Ansell
On examination there was a fixed flexion contracture of the right hip with adductor spasm; the left hip had some loss of movement but no pain at this time. Investigation showed a normal erythrocyte sedimentation rate $(7-17 \mathrm{~mm} / \mathrm{h}$, Westergren) and differential sheep agglutination titre $1: 1$, latex negative, antinuclear antibody $>6$ (normal). $X$-ray of the pelvis showed bilateral protrusion (Fig. 2a). Despite traction and exercises, symptoms in the right hip worsened and 6 months after the onset of pain in the right hip the left hip became painful. Flexion contractures increased; both hips became more limited although the pain disappeared. Radiologically, protrusio which had developed by

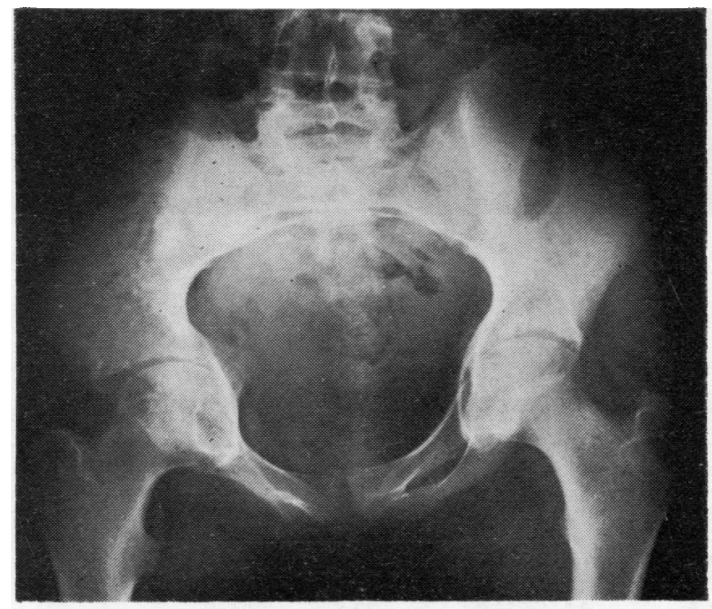

(a)

Fig. 2 (a) D.F. x-ray of hips aged 11, 3 years after onset of an abnormal gait; (b) progressive changes over 1 year; (c) aged 15, before arthroplasty. 
the age of 11 progressed with degenerative changes supervening (Fig. $2 b, c$ ); the joint cartilage space was maintained superiorly. By age 16 she was so disabled that bilateral total hip replacement was undertaken.

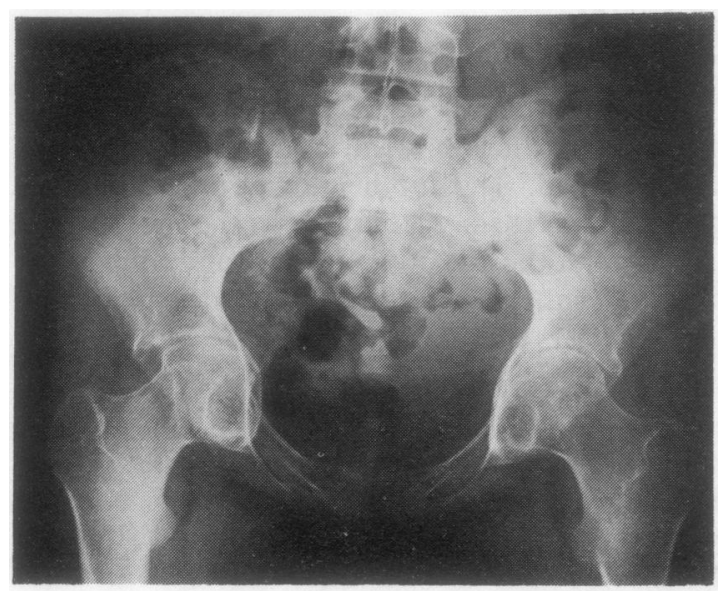

(b)

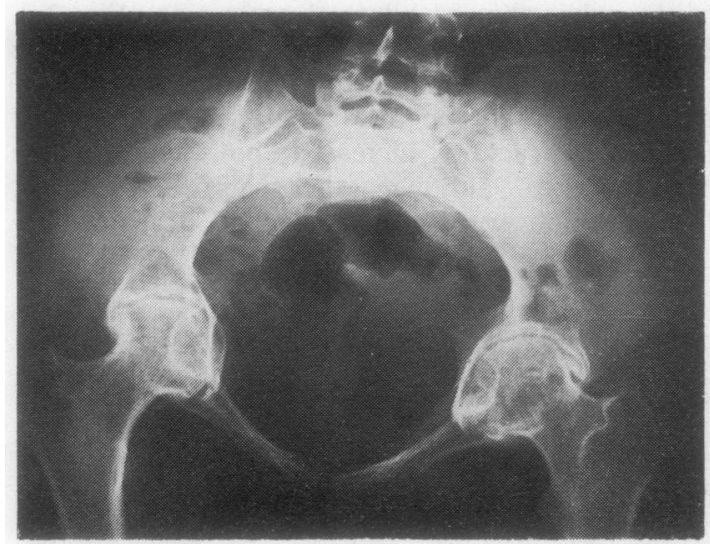

(c)
FAMILIAL ASPECT

The mother and D.F.'s 8 sibs were examined a pelvic $x$-rays taken. At this time one brother (B. complained of hip pain. The mother and another brother (T.F.) were noted to have minimal limitation of hip movement (Fig. 3). The father and previous generations of the family were unavailable for exmination.

The criteria for diagnosis of protrusio acetab商i depend on anteroposterior $x$-ray of the pelvis ahd are: (1) crossing of the teardrop line of Köhler by the line of the acetabulum (line from the pelvic border of the ilium to the medial border of the ischium, see Fig.4); (2) the VCE angle of Wiberg (1939), betwe the perpendicular drawn through the geometeic centre of the femoral head and a line drawn through to the outer edge of the acetabulum (Friedenberg, 1953; Hooper and Jones, 1971). Other useful

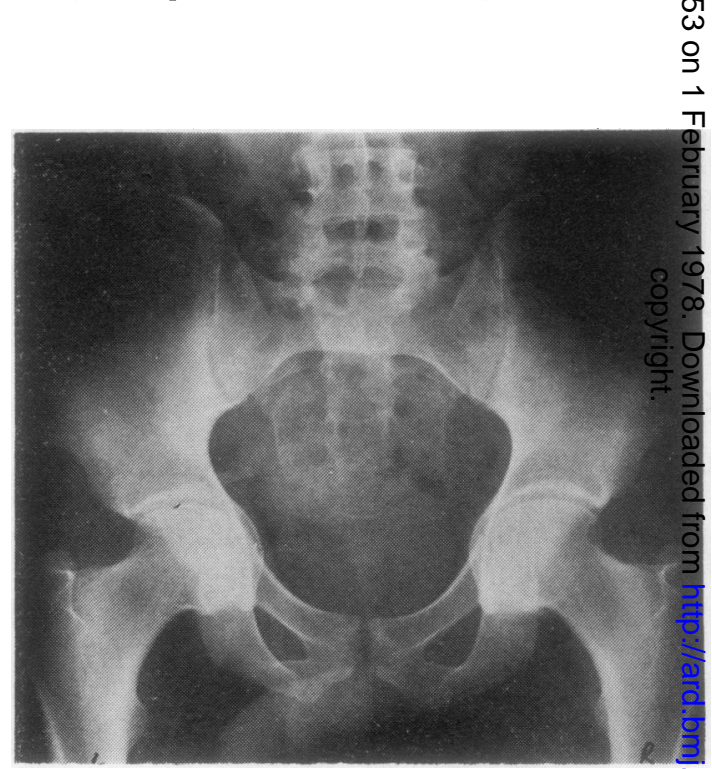

Fig. 3 X-ray of brother, T.F., aged 20 years

Table Radiological features in affected family members

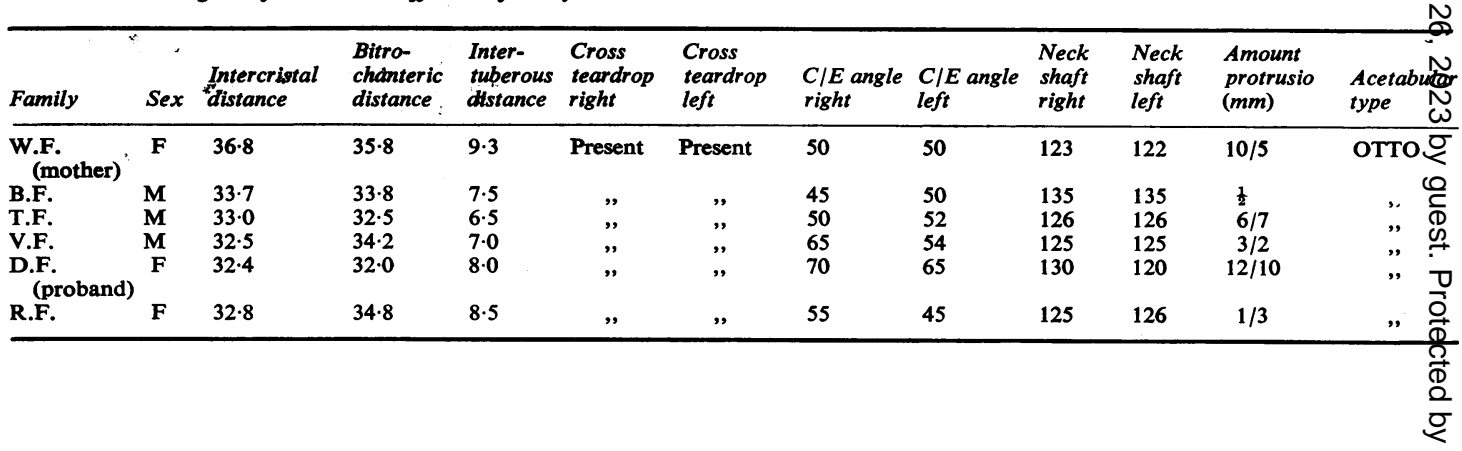




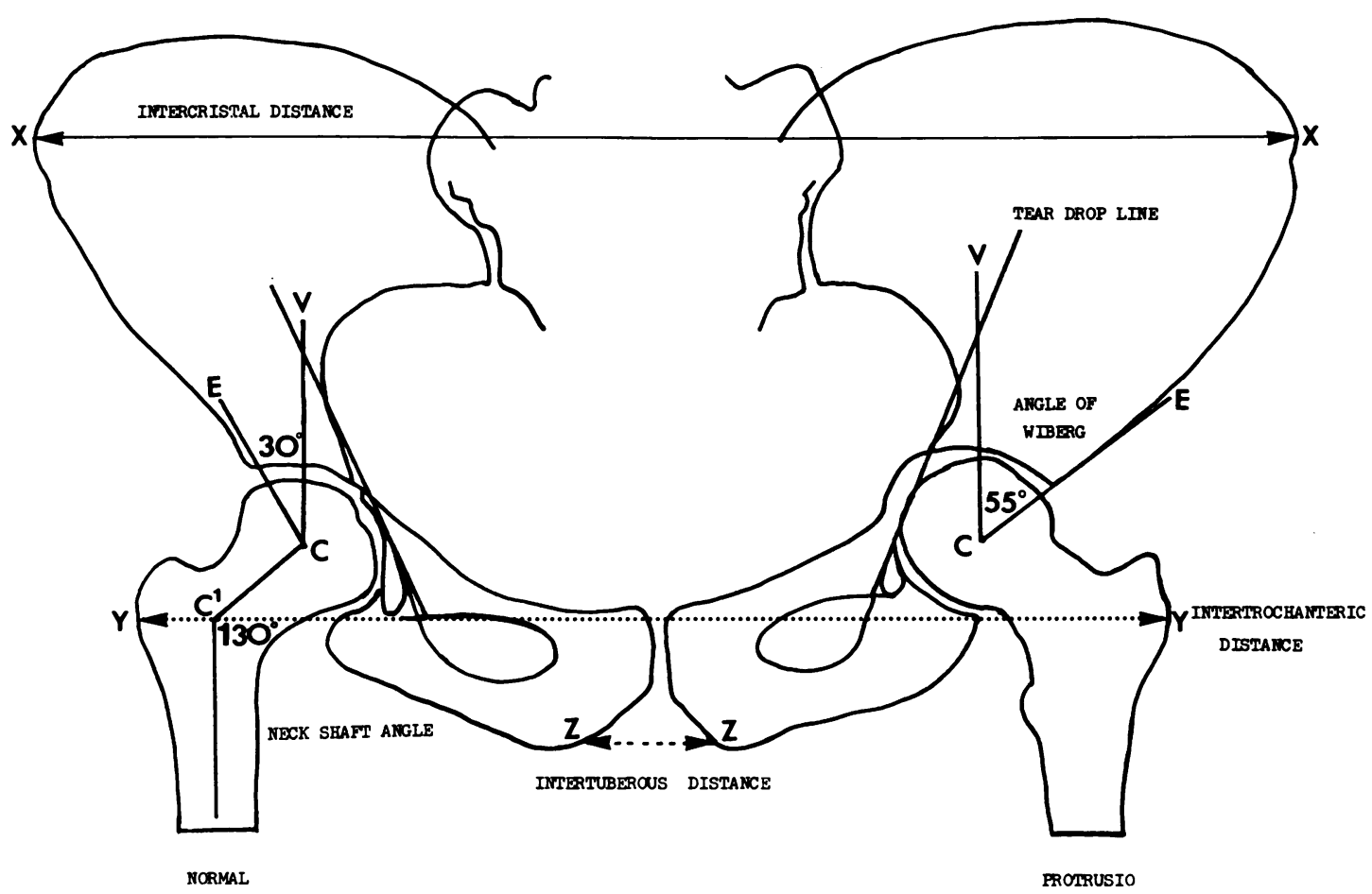

Fig. 4 Measurements required for diagnosis.

measurements noted by Gilmour (1939) include: (a) increased intercristal diameter; (b) reduced bitrochanteric diameter; (c) less than normal intertuberous distance (Fig. 4).

An anteroposterior $x$-ray showed that the mother and 4 of the patient's sibs each fulfilled all the criteria for protrusio (i.e. $\mathrm{C} / \mathrm{E}$ angle above $45^{\circ}$, crossing of the teardrop, intercristal distances greater than normal), though no member had bitrochanteric distances less than normal (Table). The 3 younger members of the family showed no radiological change.

\section{Discussion}

The radiological diagnosis was first made by Schertlin in 1910. The aetiology is not known, though Eppinger (1903) suspected a primary failure of ossification of the Y cartilage, as did Golding (1934). Gilmour (1939) thought premature fusion of the $Y$ cartilage was important. This normally unites between 20 and 25 years, although others have cited an earlier date, around the sixteenth year (Golding, 1934). Alexander (1965) thought that failure of remodelling led to the development of a deep acetabulum and that factors such as premature fusion, especially in females, and also coxa vara played a part in this process. He also noted persistent beaking of the $\mathrm{Y}$ cartilage as a feature in the development of this deep acetabulum.

The morphological changes in the femoral head of this patient were essentially those of fibrocartilaginous replacement. The left femoral head showed grossly (Fig. 5) a large lateral flange (osteophyte) and

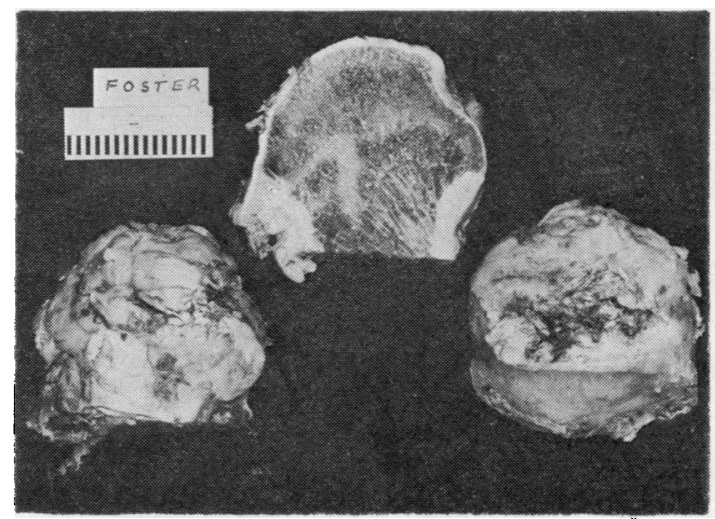

Fig. 5 D.F. gross section and anterior and posterior surface of the femoral head. 
its surface consisted almost entirely of fibrocartilaginous areas separated by crevices and adhesions. Coronal section (Fig. 6) showed a small area of original hyaline cartilage (Fig. 7) with marked deep proteoglycan production at the outer margin of the

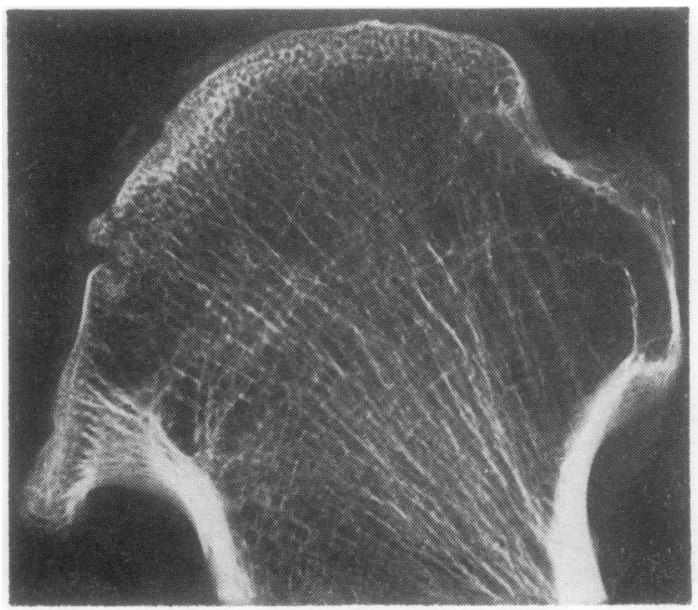

(a) old head but this was covered by and extendea laterally over this osteophyte by fibrocartilage Medial to this there is a depressed area showing remodelling with osteoclastic resorption. Elsewhete fibrocartilage covers the surfaces and extends dow

Fig. 6 D.F. (a) x-ray of femoral head. (b) Section, low power, of coronal which shows on the lateral side (left) an osteophyte covered with fibrocartilage, and medial to this are the remains of the original hyaline cartilage of the $\Omega$ femoral head covered superficially by a thin layer of fibrocartilage. Proceeding medially there is then an artefactualo . defect and then at the superior pole (the main weightbearing area) there is some bony sclerosis and a traumatogenic $\overline{\overline{0}}$. erosion with ossifying fibrocartilage within the marrow spaces. More medially the whole of the rest of the surface is occupied by fibrocartilage, interrupted only by a fibrocartilaginous intrusion at one point. More medially still there is a depression lined by fibrous tissue and finally a small boss on the medial surface covered with fibrocartilage.

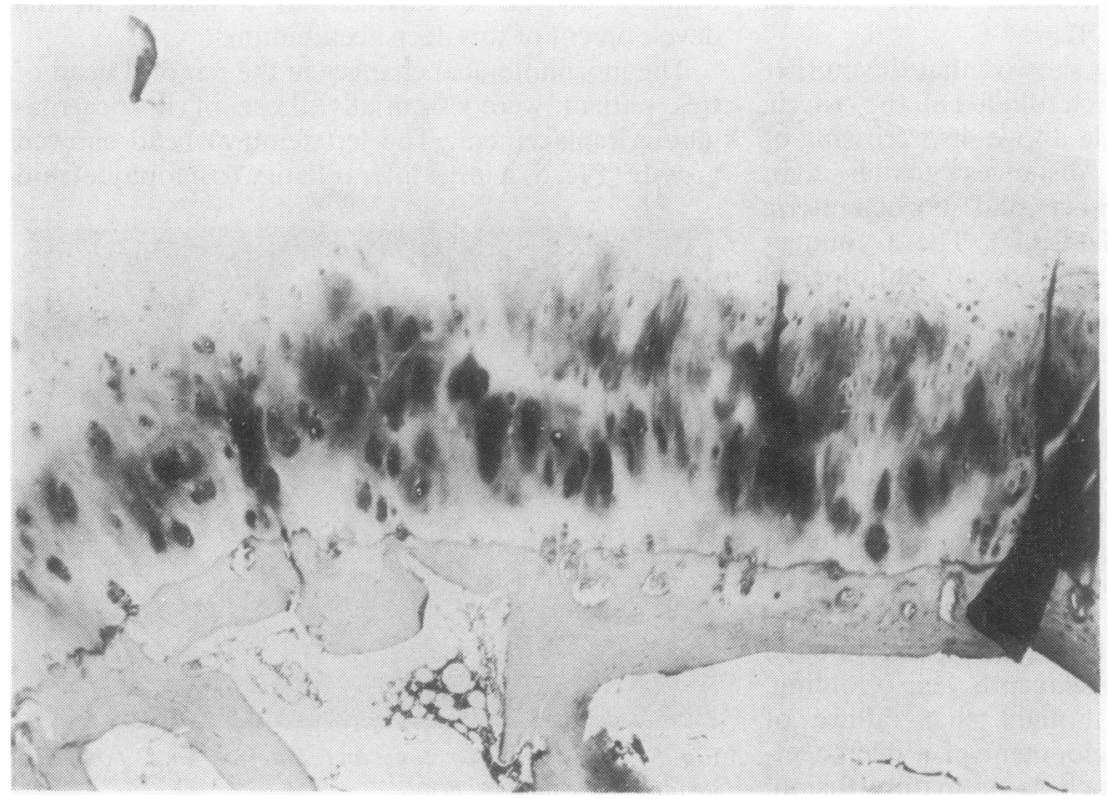

Fig. 7 D.F. High power $\mathbb{8}$ hyaline cartilage from femoral head. H.E. $\times 36$. 
into the bone in several areas (Fig. 8). Bone sclerosis is seen on the superior surface and in the flange. There is no recognizable abnormality of the bone, although evidence of remodelling is present. These are adaptive changes, but as there is no evidence of previous eburnation there must have been creeping substitution of fibrocartilage.

The familial nature of the disorder was first recognised by Rechtman in 1936 and has been confirmed by many (MacDonald, 1971), including in twins (Bilfield et al., 1973). No other clinical features were noted but a case discovered by Yeoman (1962) showed a septal defect and deformities of the digital interphalangeal joints. The unusual feature in our case was the severity of the pain and the rapid development of fixed flexion deformities.

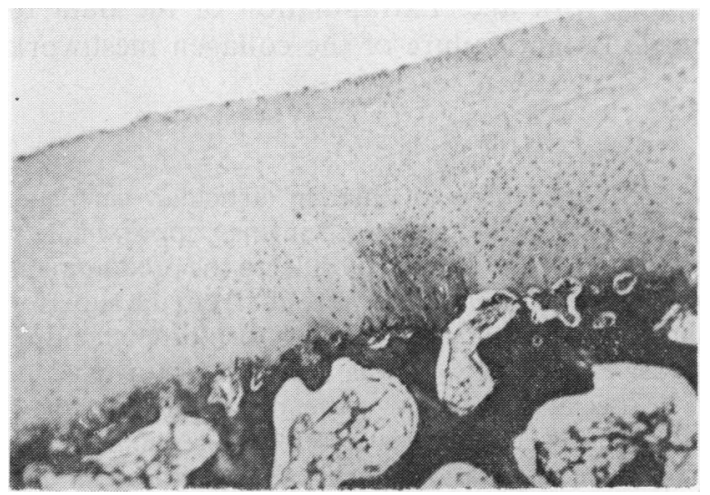

Fig. 8 D.F. High power fibrocartilage replacement of femoral head. H.E. $\times 20$.

\section{References}

Alexander, C. (1965). The aetiology of primary protrusio acetabuli. British Journal of Radiology, 38, 567-580.

Bilfield, B. S., Janecki, C. J., and Evarts, C. M. (1973). Primary protrusion of the acetabulum. Clinical Orthopaedics, 94, 257-262.

Eppinger, H. (1903). Pelvis-Chorbak; coxarthrolithesisBecken. (Festschir. R. Chrobak) Beiträge zur Geburtshilfe und Gynäkologie, ii, 176-235.

Friedenberg, Z. B. (1953). Protrusio acetabuli. American Journal of Surgery, 85, 764-770.

Gilmour, J. (1939). Adolescent deformities of the acetabulum and investigation into the nature of protrusio acetabuli. British Journal of Surgery, 26, 670-699.

Golding. F. C. (1934). Protrusio acetabuli (central luxation). British Journal of Surgery, 22, 56-62.

Hooper, J. C., and Jones, E. W. (1971). Primary protrusion of the acetabulum. Journal of Bone and Joint Surgery, 53B, 23-29.

MacDonald, D. (1971). Primary protrusio acetabuli. Journal of Bone and Joint Surgery, 53B, 30-36.

Otto, A. E. (1816). Seltene Beobachtungen zur Anatomie, Physiologie und Pathologie gehörig. Holäufer, Brealau.

Overgaard, K. (1935). Otto's disease and other forms of protrusio acetabuli. Acta Radiologica, 16, 390-420.

Rechtman, A. (1936). Etiology of deep acetabulum and intrapelvic protrusion. Archives of Surgery, 33, 122-137.

Schertlin. (1910). Ueber einen fall von intrapelviner vorwolbung und centraler wanderung der hultpfanne. Beiträge sür Klinischen Chirurgie, 71, 406-419.

Wiberg, G. (1939). Studies on dysplastic acetabula and congenital subluxation of the hip joint. Acta Chirurgica Scandinavica, Suppl. 58, 1-135.

Yeoman, P. M. (1962). Protrusio acetabuli. Proceedings of the Royal Society of Medicine, 55, 358-359. 